\title{
Kinematic analysis for Super Solo Positions in Speed
}

\section{Ball}

\section{Dr/ Ahmed Abd Elmonim Alseuofy * \\ Introduction and research problem:}

All movements of the human body are subject to the laws of mechanics, because every human movement considered a mechanical movement resulting in change of the place of bloc parts in space and time together.

The utilization of sports movement within a particular sporting activity called the athletic skill. For every athletic skill there is an essential mechanical target a player seeks to achieve. These mechanical targets, including a boost or throw different shapes and weights tools, differ in goals from achieving either greater horizontal distance or larger vertical height, precision element availability, overlapping precision and speed elements to ensure the effectiveness of achieving the goal which requires investment in the movements of the body parts including everything from positions, rates of movement, rhythm and synchronization so that these movements achieve best results.(8)

Speed-ball is one of the racket sports. It is characterized by ongoing dynamic that requires rapid reaction and very fast kinetics capacities which consist of repeating the same skill performance as its mechanical goal requires high levels of speed at a specific time.(9)

Speed-ball competitions are divided into super-solo games or playing against a competitor.

Super solo game: in which the player is the one who performs alone against the clock in an attempt to hit a ball with a racket or two to score the maximum number of correct strikes during certain time in four positions.

The player in super solo games has to play four positions. $\mathrm{He} / \mathrm{she}$ chooses freely the starting position and the order of positions.

One racket left hand one racket right hand

* Assistant Prof., Department of Sport Movement Science, Faculty of Physical Education for Boys, Helwan University, Egypt. Assiut Journal For Sport Science Arts 
Two rackets forehand - two rackets backhand

Duration of each of the four positions is one minute for the general stage, men or women.(10)

A half-minute period separates each position from the following one, to change the profile in the play and prepare for the next position, and change rackets. This time applies to all competing players in all ages.

Speed-ball has an Egyptian origin, and Egypt won 27 consecutive

World

Championships, the last world championships in Krakow, Poland in 2015. There's not to the knowledge of the researcher any motion analysis is based on the characterization of technical performance to the different hits in super solo competitions for world champions.

So the researcher tries to analyze the Kinematic characteristics to hit the ball in the four positions in super solo games for the world champion and record-holder in 2016 by using kinetic analysis programs of the movement of body parts and the racket.

Research Objectives:
1- Identify the temporal distribution of the hits in the four positions of super solo playing.

2- Identify the characteristics of some Kinematic curves in the four positions of super solo playing (displacement - speed). 3- Identify the angular change for some of the body joints in the four positions of super solo playing.

\section{Research Hypotheses:}

The researcher set the research hypotheses in the form of questions that correspond to the descriptive aspect of studying the characteristics of the technical performance of the studied skill:

1- $\quad$ Are there differences in the temporal distribution of each of the four positions?

2- What are the amounts of horizontal and vertical indentation for the body's center of gravity during performing the four positions?

3- What is the angular velocity of the head of racket in each position, and are there differences between the right and left hand speed during the performance?

4- Is there a change in the amount of the angular change between the right and left hand 
of the hiting arm during performance?

\section{- Research Methodology:}

The researcher used the descriptive method because it's suitable to the nature of research based on the kinetic analysis program (Win Analyze).
The research sample was selected purposively, and it consists from one player, namely the world champion in the last three championships and the record-holder of number of hits, who scored 606 hits in the world championship Poland 2015.

\section{- Research Sample:}

\section{Table (1) the characterization of research sample}

\begin{tabular}{c|c|c|c}
\hline \hline Player's Name & Age & Height & Weight \\
\hline \hline Mohammad Nagy & 21 years & $190 \mathrm{~cm}$ & $83 \mathrm{kgm}$ \\
\hline \hline
\end{tabular}

- Appliances and tools used:

- Video Camera 30 frames /second.

- Kinetic analysis program (Win Analyze).

Given the scarcity of research in field of motion analysis for speedball skills unlike the rest of other racket games that's many researchers have studied aspects of descriptive and technical considerin, where each of "Huang, et al." (2014), :Martin et al." (2013), Abrams, et al." (2011), Kuntze, et al." (2010), Tanabe. Ito A. (2007), analyzes the motor during a performance of some of skills in racket games, They agreed all of the Moreno, et al." (2015), Creveaux, et al." (2013), "Creveaux, et al." (2013), "Martin et al." (2013),
"Reid et al" (2008), "silva et al." (2006). Studying the angular change during the performance skills in racket games, while all of the agreed (2016) "Ryan. Et al." "Reid et al." (2015), "Whiteside D et al." (2014), "Rogowski, et al." (2014), "Antunez, et al." (2012), "Martin, Bideau, et al." (2012), "Girard, et al." (2005), "Abdel Nabi and Sharif AlAwadi" (2001) the importance of the study of biomechanical characteristics and performance technique during the performance of different strikes.

\section{Exploratory and Main Experiments:}

The exploratory experiment has been conducted at the laboratory of the Faculty 
of Physical Education for Boys, at El-Haram St., to check the availability of video and imaging angles.

\section{Statistical treatment:}

The researcher used Excel program to work on the curves of the research and took the results from the appliances and tools used directly, in addition to the percentage rates with proportions of the times of performance.

\section{Terms used in the research}

Speed-ball - individual play - kinetic analysis

\section{Results and Discussion:}

First: distribution of time and percentage of each $15 \mathrm{sec}$ During the Performance in super solo:

Table (2)

Number of strikes every 15 seconds Skills performance

\begin{tabular}{l|c|c|c|c|c|c}
\hline \hline & & $\begin{array}{c}\text { First } \\
\text { quarter }\end{array}$ & $\begin{array}{c}\text { Second } \\
\text { quarter }\end{array}$ & $\begin{array}{c}\text { Third } \\
\text { quarter }\end{array}$ & $\begin{array}{c}\text { Fourth } \\
\text { quarter }\end{array}$ & Total \\
\hline \hline \multirow{2}{*}{$\begin{array}{l}\text { One } \\
\text { Racket }\end{array}$} & right hand & 42 & 38 & 39 & 38 & 157 \\
\cline { 2 - 7 } $\begin{array}{l}\text { Two } \\
\text { racket }\end{array}$ & left hand & 40 & 38 & 36 & 35 & 149 \\
\cline { 2 - 7 } & Forehand & 38 & 36 & 34 & 36 & 144 \\
\hline \multicolumn{2}{l}{ Total } & 39 & 41 & 38 & 38 & 156 \\
\hline \hline
\end{tabular}
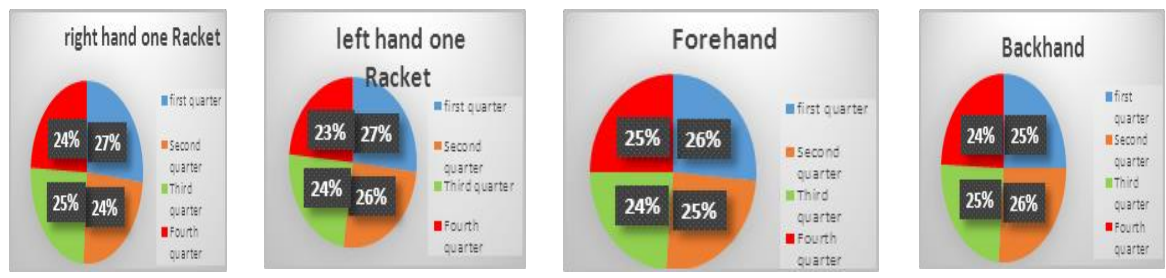

Chart (2) the percentage of performance phases 


\section{3}

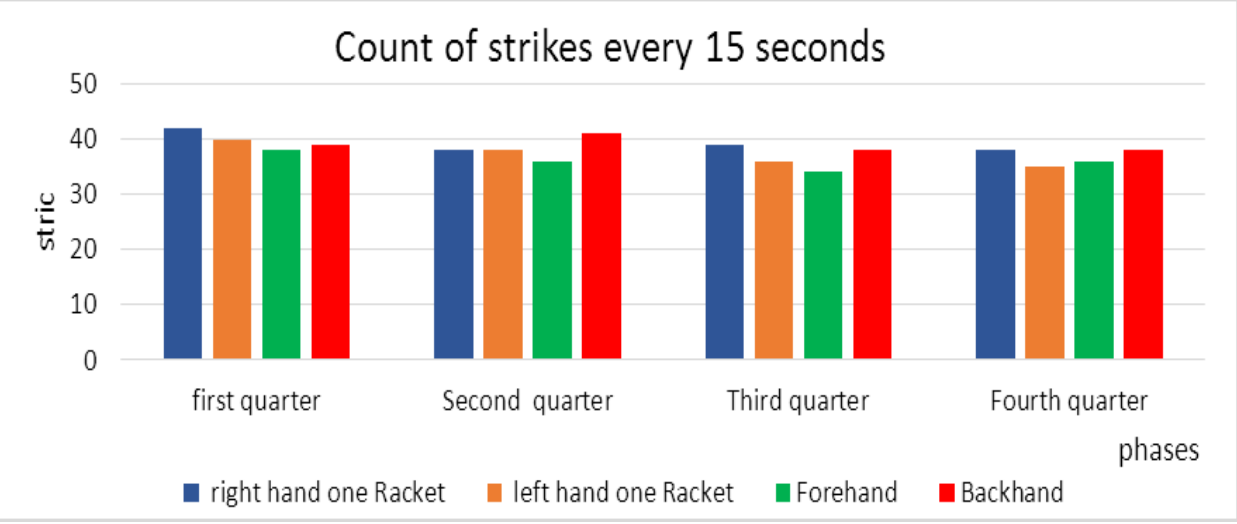

Chart (1) individual phases time and total time of performance
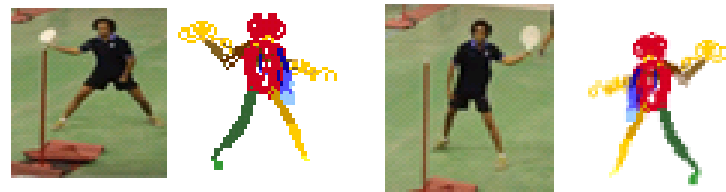

From table (2) and (figure 12 ,) which reflect the temporal distribution and the percentage of each (15 seconds) from the time of the four positions, we found that the best rate for hits was in the first quarter for the right hand at score of (42) hits, and the lowest hits rate was (35) hits in the second quarter by the left hand. The percentage each quarter of the positions recorded contributed to the score witnessed a noticeable decrease in the third and the fourth quarters in all playing positions. This might be due to muscular and
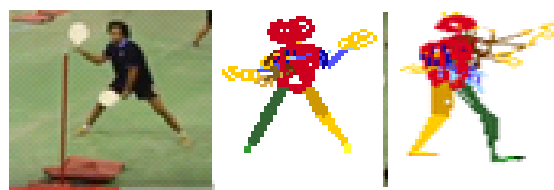

nervous fatigue at the end of every minute.

With respect to the total number of hits in each position, the highest rate of strikes was for the right hand (157 hits) which is the hand the player started with in the competition, and the lowest total strikes in a minute was for playing by fore-hand only (144 hits) and was ranked the third position in playing.

Second: Horizontal and vertical displacement amount of the body's center of gravity during performing the positions in the Super Solo: 
Table (3)

The highest and the lowest value for the center of gravity body $(\mathrm{Cm})$

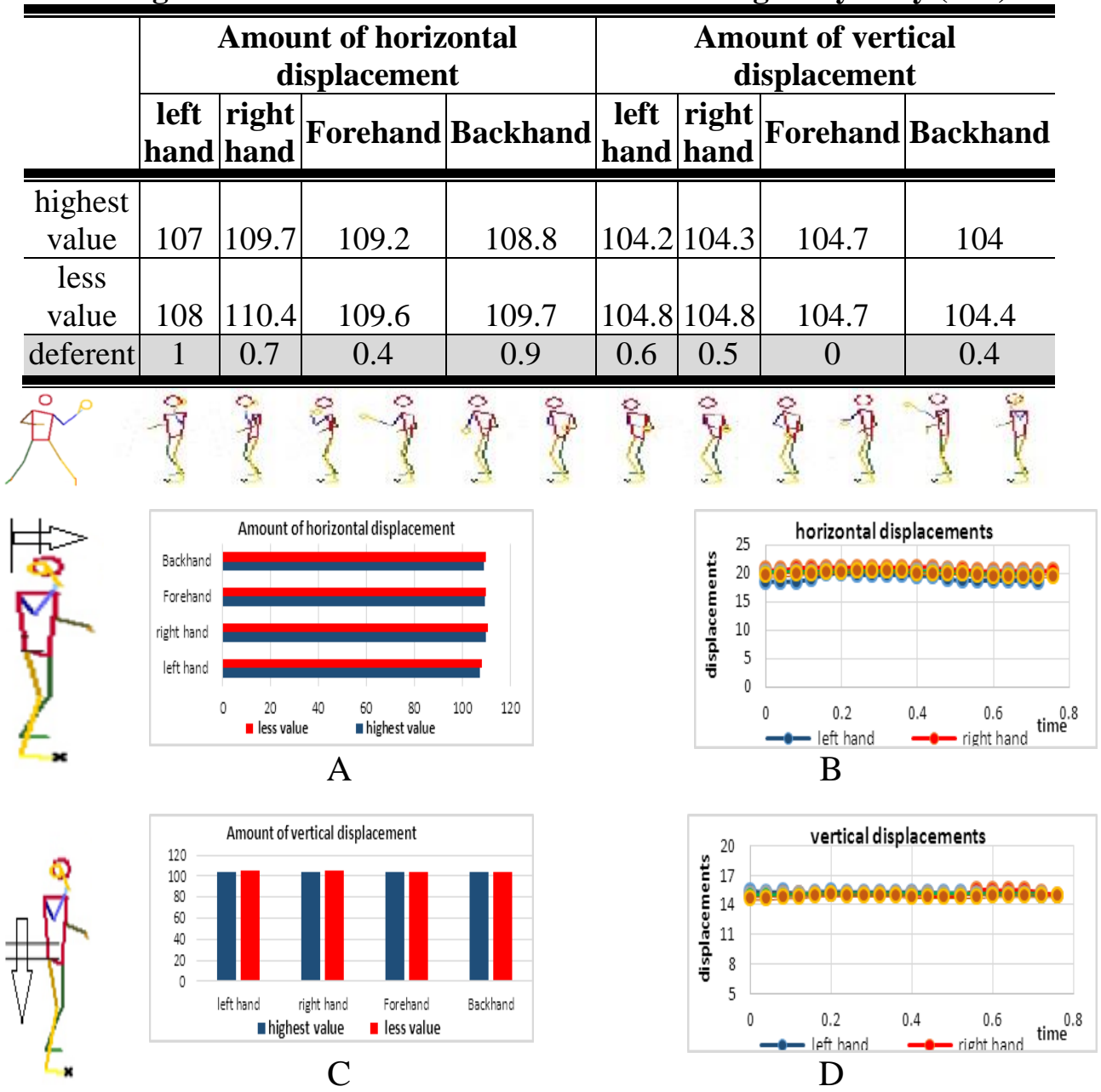

Chart 3. Horizontal, vertical displacement during the performance of four position. From table (3) and figure (3), we find that the rate of change in the body's center of gravity is negligible for both vertical and horizontal displacements in terms of the

ups and downs or forward and backward. This can be explained by the player's ability to keep the body's center of gravity in a fixed point as a basic requirement to meet the ball in the same place, not to waste time in modifying body positions, and for the

Assiut Journal For Sport Science Arts 
racket to be in a constant kinetic path. The highest amount of change was to the bottom in the horizontal displacement, and it was the largest in the left hand playing position and reached $0.6 \mathrm{~cm}$. However, for amount of change in the vertical displacement the left hand playing position has also recorded the highest change rate by $1 \mathrm{~cm}$. The researcher attributed this result to the player's nature of being righthanded in real life. Since right and left hand skills could not be matched and the preference is to the used hand in the single playing competitions against another player, which is the right hand for the player in the study sample.(26)

\section{Third: Vertical and horizontal displacement and resultant}

\section{Velocity for head racket $(\mathrm{cm} / \mathrm{s})$}
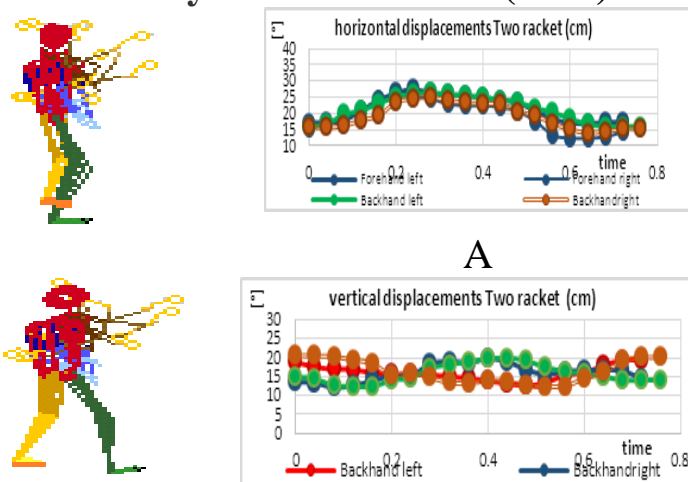

A
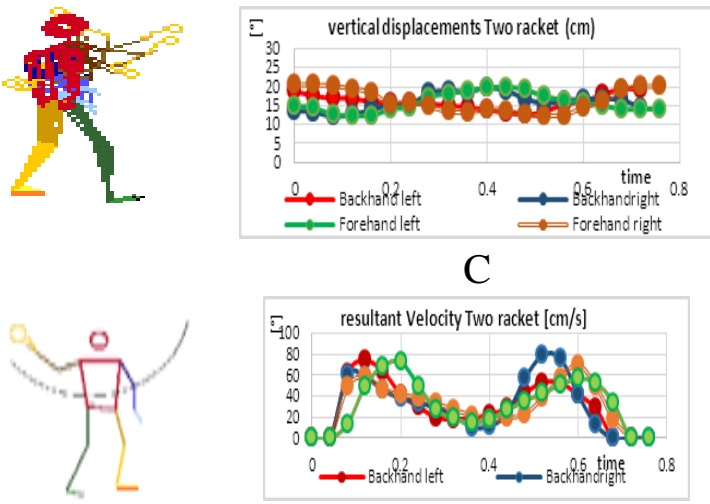

E

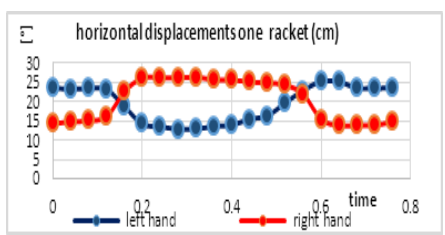

B

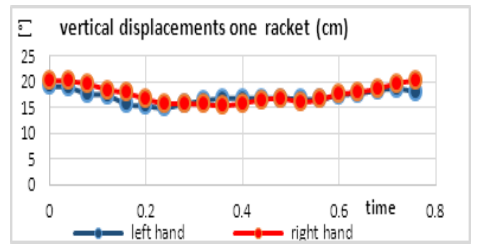

D

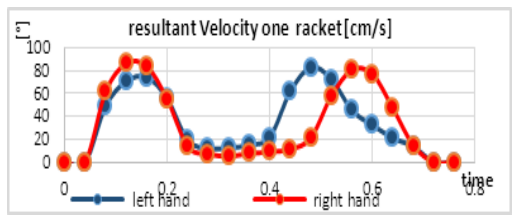

$\mathrm{F}$

Figure 4: shows resultant Velocity for head racket

From figures number (4a-b-c-d), we find that there is a great convergence in the rate of results of the horizontal and vertical displacements for the racket head path in all positions and for the two rackets, which illustrates the excellent training condition for the 
performance of the skill by both hands, represented in keeping the tracks fixed to hit the ball. However, the difference was clear for resultant Velocity figure (4EF). So for the super solo playing we found that superiority of the right hand position versus left hand position, which was shown in the rate of hitting the ball by the right hand which was higher than the left hand by 8 hits. The best acceleration of the racket head was in the start-up stage when moving to meet the ball, since the resultant Velocity recorded was $(86.22 \mathrm{~cm} / \mathrm{s})$ vs. (74.26 $\mathrm{cm} / \mathrm{s}$ ) for the left hand. Additionally, hitting in the back-hand position recorded better resultant Velocity than the hitting ball in the forehand position which recorded $(79.3 \mathrm{~cm} / \mathrm{s})$ vs. $(72.8 \mathrm{~cm} / \mathrm{s})$ for hitting the ball by the face of racket. These two numbers were for the right hand. This can be attributed to the small range of anatomical motion when hitting the ball by the back of the racket. The superiority of speed for the right hand will always remain for players who are righthanded in their daily lives. (25)

\section{Fourth: the angular change of joints of the hitting hand}

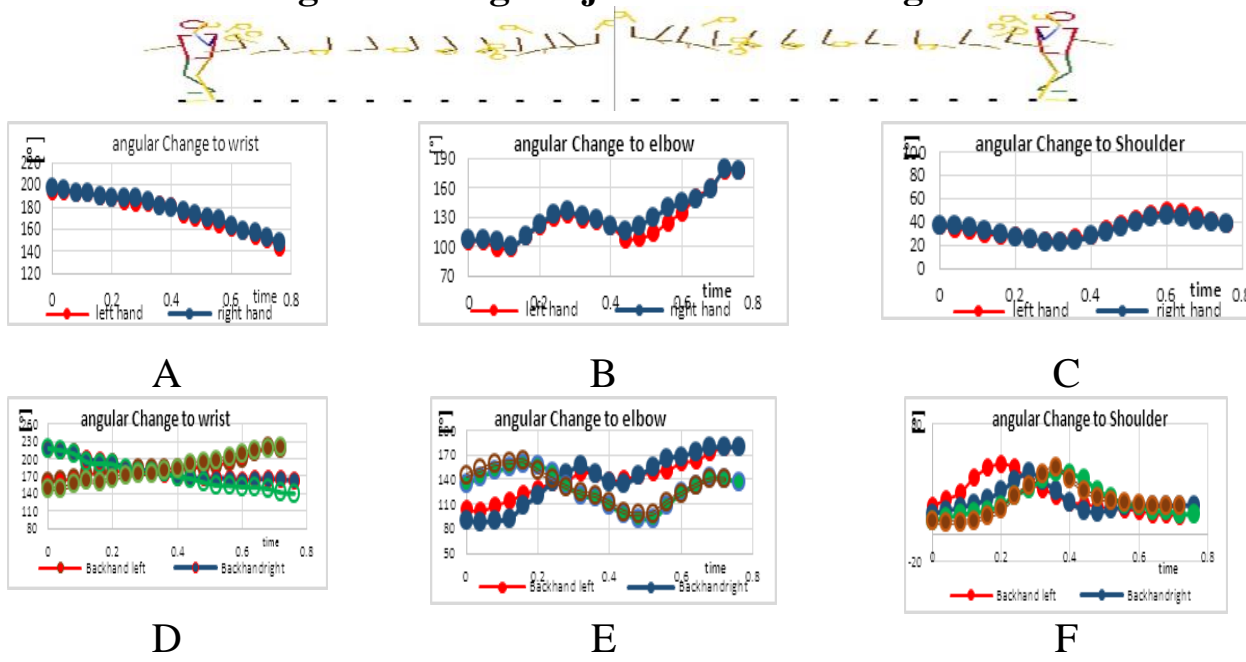

figures (5) the angular Change to some striking foot joints $\left(^{\circ}\right.$ ) 
From figures (5a-b-c), which show the angular change of the hitting arm during the two playing positions with one racket, we found that angles of the wrist, elbow, and shoulder angles are convergent and the differences do not exceed $\left(3^{\circ}\right)$ between right and left hand playing positions. The researcher attributed that to the impact of training from right to left hand reaches almost to conformity.

From figures (5 d-e-f), which show the angular change of the joints of the hitting arm during performing fore-hand and back-hand playing positions in the Super Solo, we found that there is an inverse relationship between the angles of the right and left arms due to the process of swapping hits. So, when one of the hands hits the ball and it is in the largest kinetic extent and the angle is obtuse, we find that the angle of the other hand is acute so as to achieve a dynamic smooth and balanced work, good swapping between the rackets without colliding with each other and providing the best path for the racket. We find that in the swapping stage the player moves the racket with suitable angles to reduce the air friction, and to provide greater speed to reach the ball. The angular change of the wrist joint recorded an angle ranging from $\left(173^{\circ}\right)$ to $\left(185^{\circ}\right)$, the back-hand hitting position was less than the fore-hand hitting position which is normal because of the anatomical status of the elbow and shoulder joints during the performance of back-hand hits with a racket inside by the wrist joint to provide a suitable angle to hit the ball. The figures of the angular change of the shoulder joint in the position of hitting the ball by the face of the racket were somehow low, especially in the last stage when touching the ball, and the player must pay attention to open the angle to allow the arm to do the whipping movement and hit the ball more strongly, especially for the left shoulder joint, as the increase in the shoulder angle leads to the full arm retraction process and this could be the reason for the player declined results in that position as he scored the lowest rate among the four positions by (144) hits/min.

The angular change for some of foot joints $\left({ }^{\circ}\right)$ 


\section{8}
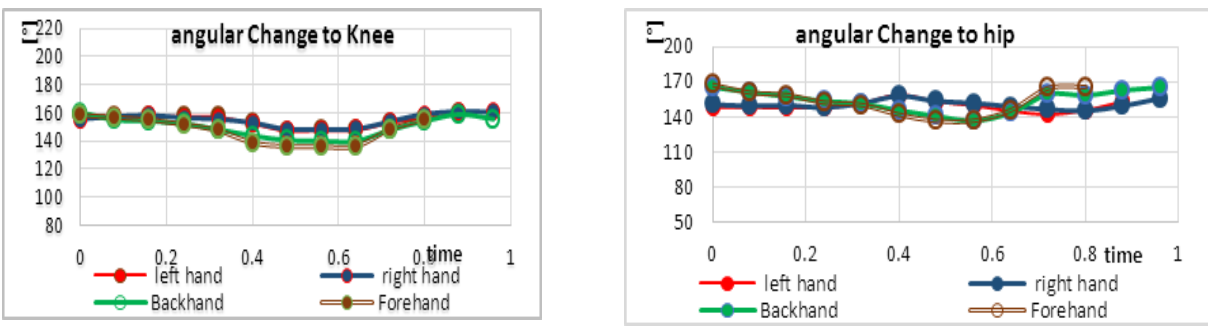

Figure 6. the angular Change to some foot joints $\left({ }^{\circ}\right)$

From figures (6 A-B), which show the angular change of the feet joints during the performance of the four playing positions, we find that the rate of change is very appropriate because of the player's anthropometric measurements where his length exceeds $190 \mathrm{~cm}$ and speed-ball mast height is $(170 \mathrm{~cm})$. The average angle of the knee at the beginning of the hit ranged from $\left(160^{\circ}\right)$ to $\left(155^{\circ}\right)$, and the lowest rate of change of the angle of the knee was $135^{\circ}$ in the position of fore-hand hitting and I think the player must be alerted to take into account to extend the knee slightly to $\left(143^{\circ}\right)$.

\section{Conclusions:}

- $\quad$ The best rate of hits was in the right hand playing position (157 hits), and the lowest rate was to play forehand only with two rackets (144 hits), with a difference of $(9.02 \%)$, which is a big difference between the two positions.

- $\quad$ Back-hand hits are better than fore-hand hits with a difference of $(8.33 \%)$, which is also a big difference between the two positions.

- Lowest rate of hits appeared in the third and fourth quarters of the minute of each position, whereas the difference between the first quarter and the third or fourth quarter was $(7 \%)$ for the right hand position, $12 \%$ for the left hand position, $(5.26 \%)$ for the position of playing fore-hand only with two rackets, and finally $(7.31 \%)$ for the position of playing backhand only with two rackets.

- $\quad$ The speed of racket head in the forehand hits is greater than the speed of racket head in the strikes the backhand hits.

- The angular change of hitting hand joints in all position of the right and left hands matched, except for the 
angle of the shoulder of the left hand.

- $\quad$ Feet angles depended on the player's anthropometric measurements. The angular change of the knee joint in all positions ranged from $\left(135.8^{\circ}\right)$ to $\left(159.23^{\circ}\right)$, the lowest average of angular change was in the position of playing with both hands backhand only $\left(145.5^{\circ}\right)$, and the highest average of angular change of the knee joint was playing with the right hand.

- The angles of the ankle ranged from $\left(136.5^{\circ}\right)$ to $(167.4$ $\left.{ }^{\circ}\right)$, the lowest average of angular change of the ankle was in the position of playing with the left hand $\left(149.1^{\circ}\right)$, and the highest average of the angular change of the ankle joint in the position of playing with both hands back-hand only $\left(152.8^{\circ}\right)$.

\section{Recommendations:}

1. Reconsidering the order of the positions and try to start with the position of the lowest number of hits.

2. Paying attention to endurance and speed exercises, to increase the endurance time of each position for more than 60 seconds in order to overcome the low rate of hits in the third and fourth quarters of the minute.

3. Paying attention to the kinetic analysis of other champions and making comparisons with their own curves.

4. Studying the ideal standing position and the distance between the feet.

5. It is essential to adjust the height of the mast in speedball for juniors to correspond with their anthropometric measurements.(2)

\section{List of references}

\section{Abdel Nabi and Sharif} AlAwadi (2001): Technique transmission characteristics of the blow in the sport of tennis, the scientific journal of the Research and Studies in Physical Education, Faculty of Physical Education for Boys, Helwan Univ.

2. Abian, Vicen, \& Sampedro.

(2012);

Anthropometric analysis of body symmetry in badminton players. International Journal of Morphology, 30(3), 945951.

3. Abrams,

Andriacchi,

Sheets, (2011); Review of tennis serve motion analysis and the biomechanics of three serve types with implications for 
injury. Sports Biomechanics10, 378-390.

4. Antunez, Hernandez, Garcia, Vaillo, (2012); Relationship between motor variability, accuracy, and ball speed in the tennis serve. Journal of Human Kinetics 33, 45-53

5. Creveaux,

Dumas, Cheze L, Mace P, Rogowski I (2013); Influence of racket polar moment on joint loads during tennis forehand drive. Compute Meth Biomechanical Biomed Eng 16: S99-'101.

6. Creveaux, Dumas, Hautier, Mac, Cheze L, Rogowski (2013): Joint Kinetics to Assess the Influence of the Racket on a Tennis Player's Shoulder. Journal of Sports Science and Medicine (JSSM) 12: 259-266.

7. Ellen Wadih Faraj (2007): New in tennis, facility knowledge, Cairo.

\section{Essam}

El-Din

Metwally (2011): kinesiology and biomechanics between theory and practice, fulfillment house, Alexandria.

9. Farouk Rajab (1999) "speedball buds, Commercial Ahram Press, Cairo.

10. Girard, Micallef J.P., Millet G. (2005): Lower-limb activity during the power serve in tennis: effects of performance level. Medicine and Science in Sports and Exercices 37, 1021-1029.

11. Huang, Hsing-Hsan Lee \& Jen-Chieh Liao (2014): Biomechanical analysis of knee and trunk in badminton players with and without knee pain during backhand diagonal lunges. Journal of Sports Science and Medicine (JSSM)

12. Kuntze, Mansfield, N., \& Sellers. (2010): A biomechanical analysis of common lunge tasks in badminton. Journal of Sports Sciences, 28(2), 183-191.

13. Martin C, Bideau B, Ropars M, Delamarche $\mathbf{P}$, Kulpa R (2013): Upper limb joint kinetic analysis during tennis serve: Assessment of competitive level on efficiency and injury risks. Scand j Med Sci Sports DOI: 10.1111/sms.12043.

14. Martin, Bideau, Nicolas. Delamarche. (2012): How does the tennis serve technique influence the serveand-volley? Journal of Sports Sciences 30, 1149-1156.

15. Martin. Bide au. Ropars., Delamarche., Kulpa. (2013): Upper limb joint kinetic analysis during tennis serve Assessment of 
competitive level on efficiency and injury risks. Scandinavian Journal of Medicine and Science in Sports

16. Moreno-Perez., Moreside. Barbado, VeraGarcia.(2015): Comparison of shoulder rotation range of motion in professional tennis players with and without history of shoulder pain. Manual Therapy 20(2), 313318.

17. Reid M., Elliott B., Alderson J. (2008): Lowerlimb coordination and shoulder joint mechanics in the tennis serve. Medicine and Science ind Sports and Exercice 40, 308-315.

18. Reid M., Giblin G., Whiteside D. (2015): A kinematic comparison of the overhand throw and tennis serve in tennis players: How similar are they really? Journal of Sports Sciences 33, 713723.

19. Rogowski, Creveaux, Cheze, and Mace, Dumas (2014): Effects of the racket polar moment of inertia on dominant upper limb joint moments during tennis serve.

20. Ryan. Lacy, Justin. Strickland, Mary. Brophy, Maryam. Witte \& Mark. Smith (2016): Exercise
Decreases Speedball SelfAdministration

Biomechanical

21. silvaT, Gracitelli.C, Saccol.F., Laurino F., BragaSilva.L.(2006): Shoulder strength profile in elite junior tennis players: horizontal adduction and abduction isokinetic evaluation. British Journal of Sports Medicine 40,513-517.

22. Tanabe. Ito A.(2007):

A three-dimensional analysis of the contributions of upper limb joint movements to horizontal racket head velocity at ball impact during tennis serving. Sports Biomechanics 6, 418-433.

\section{Whiteside D., Elliott} B., Lay B, and Reid $M$. (2014): The effect of racquet swing weight on serve kinematics in elite adolescent female tennis players. Journal of Science and Medicine in Sport 17, 124-128.

24. www.ncbi.nlm.nih.gov/p ubmed?term,Sports+Biomech 25. www.tennswarehouse.com/technologies.ht $\mathrm{ml}$. 